\title{
A Gestão do Conhecimento como recurso de inovação para Micro e Pequenas Empresas (MPEs): o modelo Enabling Knowledge Creation (EKC)
}

\author{
Knowledge Management as innovation resource for Micro and Small Enterprises (MSE): the \\ Enabling Knowledge Creation (EKC) model
}

\author{
André Anderson Cavalcante Felipe \\ Doutorando em Estudos da Linguagem pela Universidade Federal do Rio Grande do Norte. \\ E-mail: andreandersonf@gmail.com \\ Denysson Axel Ribeiro Mota \\ Doutorando em Ciência da Informação pela Universidade Federal de São Paulo. \\ E-mail: denyssonmota@gmail.com
}

\begin{abstract}
Resumo
Este artigo expõe e analisa o modelo de Gestão do Conhecimento (GC), apresenta no livro Enabling Knowledge Creation de von Krogh, Ichijo e Nonaka (2000), chamado aqui de modelo EKC, traçando suas principais etapas e formas de sua aplicação. Como objetivo analisa como as diretrizes de inovação para MPEs propostas pelo Serviço Brasileiro de Apoio às Micro e Pequenas Empresas (SEBRAE) envolvem procedimentos da GC, mais especificamente, como se configuram frente ao modelo EKC. A pesquisa bibliográfica e documental foi utilizada como aporte metodológico para apresentar o modelo EKC, e a análise comparativa como recurso para propiciar a análise das diretrizes de inovação para MPEs propostas pelo SEBRAE e a comparação das mesmas, com as etapas estabelecidas pelo modelo EKC. Os resultados mostram que as diretrizes de inovação para MPEs estabelecidas pelo SEBRAE se aproximam das etapas apresentadas pelo modelo EKC, demostrando a relevância da GC no desenvolvimento de ações que promovem formas de inovar no contexto empresarial brasileiro.
\end{abstract}

Palavras-chave: Gestão do Conhecimento. Micro e Pequenas Empresas. Enabling knowledge creation. Inovação.

\begin{abstract}
This paper exposes and analyzes the model of Knowledge Management (KM), presented in the book Enabling Knowledge Creation from Von Krogh, Ichijo and Nonaka (2000), called here EKC model, tracing its main stages and forms of application. AS objective it analyzes how the guidelines for MSE innovation proposed by the Serviço Brasileiro de Apoio às Micro e Pequenas Empresas (SEBRAE) involve procedures from the GC, more specifically, how to configure front of the EKC model. The bibliographic and documental research was used as a methodological approach to present the EKC model, and the comparative analysis as a resource to provide an analysis of the guidelines of innovation for MSE proposed by SEBRAE and comparing them with the steps established by EKC model. The results show that guidelines for MSE innovation established by SEBRAE are close to the steps presented by the EKC model, demonstrating the relevance of $\mathrm{KM}$ in developing actions that promote ways to innovate in the Brazilian business context.
\end{abstract}

Keywords: Knowledge Management. Micro and Small Enterprises. Enabling Knowledge Creation. Innovation.

InCID: R. Ci. Inf. e Doc., Ribeirão Preto, v. 6, n. 1, p. 57-78, mar./ago. 2015.

DOI: 10.11606/issn.2178-2075.v6i1p57-78 
A Gestão do Conhecimento como recurso de inovação para Micro e Pequenas Empresas (MPEs): o modelo Enabling Knowledge Creation (EKC)

\section{Introdução}

No Brasil, as Micro e Pequenas Empresas (MPEs) apresentam grande dinamismo na geração de empregos com significativos impactos na competitividade dos demais setores (SEBRAE, 2014). Indo além, elas respondem por 98\% das empresas formais do Brasil, 67\% das ocupações, $28 \%$ da receita bruta do setor formal e $20 \%$ do PIB. Em relação ao setor de atuação das MPEs, o SEBRAE afirma que 56\% fazem parte do comércio, 30\% de serviços e 14\% da indústria (SEBRAE, 1998).

As MPEs são caracterizadas por manter receita bruta anual superior a $\mathrm{R} \$ 240.000,00 \mathrm{e}$ igual ou inferior a R \$ 2.400.000,00 (BRASIL, 2006), ou, segundo classificação do SEBRAE (2014), considera-se microempresa no comércio e serviços uma empresa com até 09 funcionários e, na indústria e construção, até 19 funcionários, enquanto uma pequena empresa teria no comércio e serviços de 10 a 49 funcionários, e na indústria e construção de 20 a 99 funcionários.

No Cenário empresarial brasileiro, o Serviço Brasileiro de Apoio às Micro e Pequenas Empresas (SEBRAE), exerce um papel pioneiro no que compete à promoção de estratégias de inovação em MPEs, atuando, em todas as unidades federativas do Brasil, na condição de entidade privada sem fins lucrativos, desde 1972, com bastante destaque e know-how, tendo como, missão central,

[...] promover a competitividade e o desenvolvimento sustentável dos empreendimentos de micro e pequeno porte. A instituição atua também com foco no fortalecimento do empreendedorismo e na aceleração do processo de formalização da economia por meio de parcerias com os setores público e privado, programas de capacitação, acesso ao crédito e à inovação, estímulo ao associativismo, feiras e rodadas de negócios. Parte deste esforço ganhou visibilidade com a aprovação da Lei Geral da Micro e Pequena Empresa, em dezembro de 2006. A Lei consolidou, em um único documento, o conjunto de estímulos que deve prevalecer para o segmento nas três esferas federal, estadual e municipal da administração pública, inclusive na área tributária. [Suas] ações reforçam o [...] empreendedorismo e revelam a importância da formalização para a economia brasileira. [Seu] papel é mostrar aos milhões de micro e pequenos empresários [...] as vantagens de se ter um negócio formal, apontando caminhos e soluções, com o objetivo de facilitar o acesso aos serviços financeiros, à tecnologia e ao mercado, sempre com foco na competitividade empresarial. (SEBRAE, 2014).

Recentemente, o SEBRAE (2013) apresentou a publicação de 10 diretrizes de estímulo à inovação em MPEs:

1) Liderança inovadora, instituir um ambiente propício para a inovação, a ser iniciado pela direção da empresa e depois nos setores; 
2) Incentivar a criatividade, estimular a busca e transformação de boas ideias em oportunidades de negócio viáveis;

3) Ouça e coloque-se no lugar dos seus clientes, valorizar este tipo de fonte informacional, por ser mais barata e ter grande eficácia;

4) Saiba o que a concorrência está fazendo, conhecer os concorrentes. Avaliar seus produtos, preços, promoções, atendimento, etc.;

5) Rede de relacionamento, criar e manter relacionamentos saudáveis com parceiros, fornecedores, clientes, vizinhança, investidores;

6) Comunicação interna, promover a comunicação em todas as direções (entre colaboradores, do líder para seus colaboradores e vice-versa).

7) Comunicação externa, buscar formas dinâmicas para se comunicar, tendo em vista o mercado;

8) Reconhecimento e recompensa, reconhecer o esforço pessoal e da equipe, estabelecer objetivos claros e determinar formas de mensuração;

9) Capacitação, ampliar a capacidade de usar melhor os recursos da empresa e desenvolver produtos e serviços inovadores;

10) Voltar atrás em tempo hábil, estabelecer indicadores, de modo a se prevenir em caso de constatar que a performance da MPE está muito distante do que planejou, deve paralisar a ação e repensá-la.

Destacamos, ainda, que ações inovadoras incentivadas pelas diretrizes, induzem, em seus colaboradores, as mais altas aspirações e expectativas, tornando-os dedicados à excelência de suas tarefas e funções (SEBRAE, 2013). Para deixar mais claro a natureza de cada uma das diretrizes expostas acima, apresentaremos a seguir uma exposição geral de cada uma delas, com uma explicação dos elementos que as compõem.

A primeira diretriz, Liderança inovadora, que dentre as suas atribuições em organizações, destaca-se pela criação de condições para que as pessoas possam desenvolver os seus talentos e habilidades e aplicá-los na melhoria permanente dos resultados de seu trabalho. Os líderes devem superar as limitações e refletir sobre as competências básicas exigidas para o desempenho da liderança, um conjunto de habilidades e comportamentos que 
A Gestão do Conhecimento como recurso de inovação para Micro e Pequenas Empresas (MPEs): o modelo Enabling Knowledge Creation (EKC)

permitem a eles gerar um determinado resultado através da coordenação do trabalho em equipe. As organizações da atualidade valorizam a liderança inovadora, ou seja, aquela que trabalha em equipe e visa aos relacionamentos interpessoais (SILVA, 2011).

A diretriz Incentivar a criatividade enfatiza a necessidade das organizações estimularem a inovação e a criatividade do profissional, sendo a favor de mudanças que agregam valor ao negócio e aos próprios funcionários. O Sebrae (2013) ressalta a necessidade de espaços no ambiente organizacional que promovam o ambiente criativo, para facilitar a comunicação entre os colaboradores e, assim, incentivar a criatividade. Outros elementos que, segundo o Sebrae (2014), promovem a criatividade são: Informação, para descobrir o está acontecendo no mercado sobre a sua área de atuação; Comunicação, principalmente entre a empresa e os clientes, para saber o que o público está procurando e, assim, criar ou reinventar produtos e/ou serviços de acordo com essa necessidade; Referências, estimulando os colaboradores a pesquisar sobre as novidades no mercado.

A diretriz Ouça e coloque-se no lugar dos seus clientes, foca na satisfação dos clientes, de modo que faz-se necessário analisar os produtos e serviços da empresa nos mais diversos canais de vendas que ela se fizer presente, sempre se avaliando e verificando onde há espaço para melhorias nos seus processos. É fundamental possibilitar meios de comunicação com o cliente para obter deles o feedback e assim aprimorar os serviços prestados. Dessa forma, a necessidade estratégica nasce da impossibilidade de satisfação simultânea de interesses divergentes e da imprevisibilidade da reação de qualquer oponente, que possui valores e percepções geralmente constituídos de forma totalmente diversa (COSTA; ALMEIDA, 2005, p. 205).

Segundo a diretriz Saiba o que a concorrência está fazendo, uma organização tem que estar a par do que seus concorrentes estão realizando. A análise da concorrência é uma ação contínua que deve ser empenhada com vigor, para que se tenha uma visão clara tanto do mercado quanto da forma como o produto oferecido pode ser melhorado. O Sebrae (2013) informa que ao analisar seus concorrentes, uma organização deve desenvolver as seguintes etapas: identificar o concorrente real, analisar os pontos fortes e fracos, conhecer as oportunidades e as ameaças, e determinar a posição da organização.

No âmbito da diretriz Rede de relacionamento, Souto (2013) ressalta que a necessidade de desenvolver uma rede de relacionamento em organizações não é uma tarefa fácil, pois cada uma tem metodologia de relacionamento e linguagem diferentes, mas que 
possibilita mudanças e dinâmica diante desta evolução relacional. No ambiente virtual, em especial, é preciso respeitar o indivíduo, a sua liberdade de escolha, acompanhar o seu desenvolvimento e manter a ética no mundo organizacional diante de uma perspectiva social. Entende-se também que tudo isto provoca grande ansiedade, e é possível ver que muitas organizações entram neste universo virtual sem planejamento, apenas para conquistar o mercado. Realizar essa ação sem preparação é um ato perigoso, onde um erro pode provocar a perda da credibilidade organizacional, por não ter um propósito claro e muito cuidado para atuar nesta área de comunicação social.

A diretriz Comunicação interna tem grande valor nos processos de desenvolvimento e disseminação da informação, relacionados às ações que ocorrem nas organizações e às decisões estratégicas, daí importância de incrementar ações que apresentem os líderes organizacionais como propulsores e otimizadores de discursos capazes de favorecer o desenvolvimento das pessoas, assim como o incremento no nível de conhecimento. Os líderes devem assumir a postura do diálogo e não única e exclusivamente a de influenciar pessoas. Devem, sim, olhar para a liderança transformacional, mas também observar que ela somente será realidade a partir do momento em que possa estabelecer discursos com as pessoas com as quais se relaciona (MARCHIORI, 2008).

A diretriz Comunicação externa é um processo primordial nas organizações de diversos níveis, porém é complexa e se torna um risco quando não se sabe como realmente usá-la. Na maioria das vezes a comunicação interna é transmitida externamente, sendo que esta situação pode trazer riscos e reflexos nos resultados organizacionais internos em todas as perspectivas do negócio. É necessário filtrar informações sigilosas e tratar das diversas situações que podem ocorrer no ambiente organizacional para não manchar a imagem da instituição. Os resultados de uma organização que não passa informações coerentes e adequadas ao ambiente externo podem ser desastrosos, podendo ficar abaixo de metas e objetivos da empresa, o que afetará em seu constante desenvolvimento (SEBRAE, 2013).

A diretriz Reconhecimento e recompensa aponta não apenas para as bonificações, mas para o fato que há patamares mínimos de remuneração que devem ser pagos para não gerar insatisfação e, que a satisfação não é o oposto de insatisfação. Satisfação tem a ver, sobretudo, com a própria natureza do trabalho, do ambiente de trabalho, dos desafios específicos e do reconhecimento pelos pares, superiores e, em alguns casos, empresa e sociedade como um todo. (TERRA, 1999). Para o autor, os aspectos relacionados ao 
A Gestão do Conhecimento como recurso de inovação para Micro e Pequenas Empresas (MPEs): o modelo Enabling Knowledge Creation (EKC)

reconhecimento e a recompensa são instrumentos poderosos para atrair e reter profissionais talentosos, trabalhando com inovação nas organizações. Um dos desafios, mas que guardamos para outro artigo, é o mecanismo de reconhecimento e recompensa para a inovação, muitas vezes precisa ser implementado em organizações que já possui uma estrutura de reconhecimento e recompensa amplamente voltada para o contexto de curto prazo e operacional.

A diretriz Capacitação está relacionada ao fazer do profissional em uma organização. Nesse contexto, o profissional deve ter consciência de que seu sucesso ou fracasso depende apenas dele mesmo. Sem objetivos claros não existe ponto de chegada, e sem planejamento não é possível atingir um objetivo. Cabe ao profissional ajudar a empresa e a si mesmo, cuidando de seu marketing pessoal para que seu trabalho e resultados sejam conhecidos. $\mathrm{O}$ objetivo de qualquer profissional atualmente é tentar ser o melhor possível na sua área de atuação, mas também obter conhecimento em outras áreas. Saber muito de sua especialidade e, ao mesmo tempo, um pouco de tudo (LACERDA, 2010).

Por fim, a diretriz Voltar atrás em tempo hábil, nos chama a atenção para a optimização do tempo na organização, de modo que, as organizações estejam representadas por líderes ou administradores, que visualize o todo positivo ou negativo, que atingirá a organização com sua tomada de decisão, a fim de diminuir ou eliminar danos, falhas, transtornos e retrabalhos. Embora possamos dispor de meios tecnológicos para nos auxiliar, a capacidade de raciocínio precisa estar aliada à boa sensibilidade, ao bom senso crítico (LIMA, 2012).

Em um contexto empresarial, torna-se imprescindível estimular a criatividade e a curiosidade dos colaboradores, provocando-os a buscar, gerar e compartilhar conhecimentos, e, ao mesmo tempo, como Figueiredo (2006) nos mostra, reconhecer seus limites, solicitando ajuda sempre que necessário. Conscientes desses valores, os colaboradores / funcionários passam a ter mais disposição para cooperar e compartilhar conhecimentos de modo a perpetuá-los, preferencialmente, expressando-se em modo textual ou gráfico, com o intuito de torná-los disponíveis à organização como um todo, através da informação.

A necessidade de ações para a melhoria e o avanço das MPEs no Brasil é latente, como mostra Bin (2008). O autor afirma que para haver êxito no desenvolvimento de MPEs, é preciso uma série de fatores, dentre eles a inovação, entendida aqui como um processo de criação e apropriação social (via mercado ou não) de produtos, processos e métodos que não 
existiam anteriormente, ou contendo alguma característica nova e diferente até então em vigor.

Apesar dos esforços em políticas de inovação e desenvolvimento prestados pelo SEBRAE e demais instituições de fomento ao crescimento industrial brasileiro, percebe-se que ainda na esfera das MPEs, faz-se necessário a adesão ou atualização de procedimentos estritamente relacionados à informação e aos conhecimentos produzidos e utilizados no âmbito dessas organizações, como a gestão do conhecimento (GC).

A utilização de procedimentos relativos à GC pode promover o avanço de instituições com fins lucrativos como as MPEs, visto que, ela se apresenta como um importante recurso para áreas empresariais e científicas que lidam com a informação e seus diferentes processos de construção e disseminação de conhecimento em: organizações, instituições com fins lucrativos, entidades filantrópicas, dentre outros (FELIPE, 2011).

Ciente da importância de ações desenvolvidas pelo SEBRAE (2013) para o desenvolvimento das MPEs no Brasil, e das melhorias que a GC pode proporcionar no âmbito da inovação em contextos empresariais, o presente trabalho tem como objetivo apresentar o modelo de GC do livro “Enabling Knowledge Creation” de von Krogh, Ichijo e Nonaka (2000), analisando suas características para compará-lo com as diretrizes de inovação para MPEs estabelecidas pelo SEBRAE, com a finalidade de identificar se elas contemplam ou envolvem procedimentos da GC.

Como aporte metodológico, utilizou-se a pesquisa bibliográfica sob o viés da abordagem qualitativa, para analisar do modelo EKC e compará-lo as diretrizes de estímulo da inovação propostas pelo SEBRAE. A abordagem qualitativa apresenta características que vão ao encontro do objetivo do trabalho, como informa Bauer e Jovchelovich (2002): possui um caráter mais descritivo, indutivo; baseia-se em dados descritivos (coletados em contato direto do pesquisador com a situação objeto de estudo); molda-se ao longo do seu desenvolvimento; ausência quase total de ferramentas estatísticas; temporal e espacial.

Entende-se a pesquisa bibliográfica como aquela que se realiza a partir do registro disponível, decorrente de pesquisas anteriores, em documentos impressos, como livros, artigos, teses etc. Utiliza-se de dados ou de categorias teóricas já trabalhadas por outros pesquisadores e devidamente registradas. Qualquer espécie de pesquisa, em qualquer área, supõe e exige uma pesquisa bibliográfica prévia (GIL, 2008). 
A Gestão do Conhecimento como recurso de inovação para Micro e Pequenas Empresas (MPEs): o modelo Enabling Knowledge Creation (EKC)

Para o processo de análise foi utilizada a análise comparativa, que possibilitou a verificação das diretrizes de inovação para MPEs propostas pelo SEBRAE e do modelo EKC, bem como a comparação entre ambos, de modo a atingir o objetivo proposto pelo artigo de avaliar o atendimento dos procedimentos da GC às diretrizes propostas pelo SEBRAE.

\title{
2. Gestão do Conhecimento e as MPEs
}

Barbosa (2008), em extensivo trabalho bibliográfico, relata as diferentes vertentes e visões tanto da Gestão da Informação quanto da Gestão do Conhecimento. Cita, então, Elizabeth Davenport e Blaise Cronin (2000) para afirmar que existem, pelo menos, três formas de GC, cada uma com características, visões e conceituações próprias. Esses três "tipos" de GC, denominados de GC1, GC2 e GC3, são descritos da seguinte forma:

\begin{abstract}
A primeira, denominada por eles de GC1, tem suas bases na biblioteconomia e na ciência da informação. Aqui, a gestão do conhecimento é vista por muitos simplesmente como um produto velho em nova embalagem. Ou seja, a gestão do conhecimento não passa de gestão da informação com outro nome.

A GC2 identifica a gestão do conhecimento com a gestão do know-how e prioriza Gestão da informação e do conhecimento: origens, polêmicas e perspectivas processos e atividades organizacionais, com ênfase nas representações (ontologias) dessas atividades e capacidades. Essa perspectiva, fortemente orientada para sistemas, enfatiza a extração e o descobrimento do valor contido em repositórios de dados e de informação por meio de técnicas sofisticadas, tais como data mining e data warehouse. A propósito da perspectiva de sistemas da gestão do conhecimento, deve-se salientar que, no campo da inteligência artificial, os sistemas especialistas são também conhecidos como sistemas baseados em conhecimento (knowledge based systems). Nesse contexto, os conceitos de representação do conhecimento, engenharia do conhecimento, bases de conhecimento, são bem estabelecidos.

Por último, a GC3 tem seus fundamentos na teoria organizacional e considera o conhecimento como fator capaz de proporcionar a adaptação da empresa ao seu ambiente externo. Aqui, o aspecto central da GC é o relacionamento entre o conhecimento tácito e o conhecimento explícito. O conceito de " $b a$ ", ou o contexto onde o "conhecer" acontece, é um dos conceitos centrais na GC3. Neste caso, o que é gerenciado não é o conhecimento em si, e sim o contexto no qual ele se manifesta (BARBOSA, 2008, p. 9-10).
\end{abstract}

Percebe-se então que a GC, de forma geral, caracteriza-se como um procedimento importante para o desenvolvimento das organizações, e entre estes elementos encontra-se o incentivo à inovação. Miranda (2004) apresenta um quadro comparativo entre a GI e a GC, aqui modificado e apresentado no Quadro 1. O autor afirma que ela se encarrega de mapear o conhecimento que cada colaborador tem em potencial, e estuda os meios de explicitação deste em forma de informação registrada, passível de consulta mesmo posterior a sua saída da empresa. 
Quadro 1 - Características da GC

\begin{tabular}{|c|c|}
\hline \multicolumn{2}{|c|}{ Características da GC } \\
\hline $\begin{array}{l}\text { Foco na captura de informação tácita e sua } \\
\text { transformação em explícita. }\end{array}$ & $\begin{array}{l}\text { Utiliza a pré-cognição e a adaptação para } \\
\text { alcançar os objetivos. }\end{array}$ \\
\hline $\begin{array}{l}\text { Desenhado para o armazenamento, controle e } \\
\text { acesso distribuído da informação. }\end{array}$ & $\begin{array}{l}\text { Obtém informação de uma fonte e promove a } \\
\text { reutilização em outras situações. }\end{array}$ \\
\hline Enfatiza a colaboração e o compartilhamento. & Produtividade pela inovação. \\
\hline $\begin{array}{l}\text { Proporciona a definição pelo usuário final dos } \\
\text { relacionamentos entre a informação e suas } \\
\text { necessidades. }\end{array}$ & $\begin{array}{l}\text { Emprega tecnologia (como, por exemplo, as } \\
\text { de visualização) para a descoberta do } \\
\text { conhecimento. }\end{array}$ \\
\hline $\begin{array}{l}\text { Agrega valor para o crescimento, inovação e } \\
\text { alavancagem. }\end{array}$ & Atende a mudanças radicais e descontínuas. \\
\hline
\end{tabular}

Fonte: adaptado de Miranda (2004, p. 51-52).

Grande parte dos elementos apresentados no Quadro 1 são do escopo da CI, que, entre outras coisas, interessa-se no corpo do conhecimento relativo à origem, coleção, organização, armazenamento, recuperação, interpretação nos sistemas, estudando dispositivos e técnicas de processamento da informação (TARGINO, 1995).

$\mathrm{Na}$ vertente social da CI, mais do que comportamentos eminentemente individuais para os quais apenas o intelecto e a deliberação contribuem, conhecer e aprender são ações sociais, ou também, ações socialmente constituídas e determinadas (GONZÁLEZ DE GÓMEZ, 2000, 2004). E é com esse caráter social que von Krogh, Ichijo e Nonaka (2000) trabalham seu texto, voltando os esforços de GC para a criação e o compartilhamento de experiências de forma colaborativa e social, de modo simples e com esforços voltados à comunicação, em vez de tecnologias e técnicas de armazenamento e recuperação de informação.

É nesta perspectiva social da GC, como abordado por von Krogh, Ichijo e Nonaka (2000), e que Barbosa (2008) considera como um terceiro tipo de GC, ou GC3, que este artigo se apoia. É importante ressaltar que não é objetivo deste artigo dissecar ou discutir os diferentes conceitos de GC, apresentando aqui este breve levantamento conceitual apenas para esclarecer a visão sobre a qual este artigo foi construído.

Dentro do âmbito de atuação da CI, Mota (2011), traz uma discussão que busca esclarecer qual o modelo de GC que melhor atende às necessidades de inovação em MPEs, dentro das realidades econômica e social brasileira. Seu estudo avaliou quatro modelos de GC que foram escolhidos devido a sua criação e/ou utilização terem sido voltadas ao âmbito das MPEs, no contexto brasileiro. São eles: 
A Gestão do Conhecimento como recurso de inovação para Micro e Pequenas Empresas (MPEs): o modelo Enabling Knowledge Creation (EKC)

a) modelo de Silva Júnior (2006), criado com foco totalmente voltado às empresas de tecnologia. Inclui quatro fases principais: i) planejamento, ii) implementação, iii) execução e iv) avaliação / melhoria contínua;

b) modelo de Thiel (2002), também direcionado às empresas de tecnologia, mas, com um viés diferente, voltado para os processos da organização e sua compreensão por parte dos colaboradores. É composto por quatro fases principais: i) preparação e conscientização, ii) aquisição do conhecimento e mapeamento de processos, iii) formação da base de conhecimento, iv) socialização e aprendizagem organizacional;

c) modelo de Rumizen (2002), presente no livro The Complete Idiot's Guide to Knowledge Management, apresenta facilidade de leitura e diagramação diferenciada, em relação aos modelos já citados. Contempla cinco etapas: i) planejamento, ii) criar infraestrutura de TI, iii) modelar a cultura organizacional, iv) avaliar os procedimentos, e v) implantar melhorias;

d) modelo de von Krogh, Ichijo e Nonaka (2000), criado na obra "Enabling Knowledge Creation”, mostra que não é possível controlar ou mensurar algo intangível como o conhecimento, o que se faz, segundo os autores, é capacitar os indivíduos para a melhor criação e compartilhamento de conhecimento, pois não é possível controlá-lo, mas busca-se sua geração. O modelo descreve cinco etapas: i) instilar a visão do conhecimento, ii) gerenciar as conversas, iii) mobilizar os ativistas do conhecimento, iv) criar o contexto adequado, v) globalizar o conhecimento local.

A avaliação foi realizada com base em características das MPEs analisadas por Mota (2011) que foram identificadas como limitantes para uma eventual adoção, São elas: número de colaboradores; nível de rotatividade de colaboradores na empresa; experiência percebida nos colegas; adoção de processos por parte da organização; características desejáveis nos modelos (Envolvimento dos colaboradores, Prazo dos resultados, Definição de passos); porte dos clientes da organização, tanto de esfera pública como privada; cultura organizacional propensa à colaboração entre os pares.

Todas as fundamentações e procedimentos foram apresentados de forma sucinta em trabalho posterior (MOTA; TARGINO, 2013), e suas conclusões são aqui exibidas a seguir. 


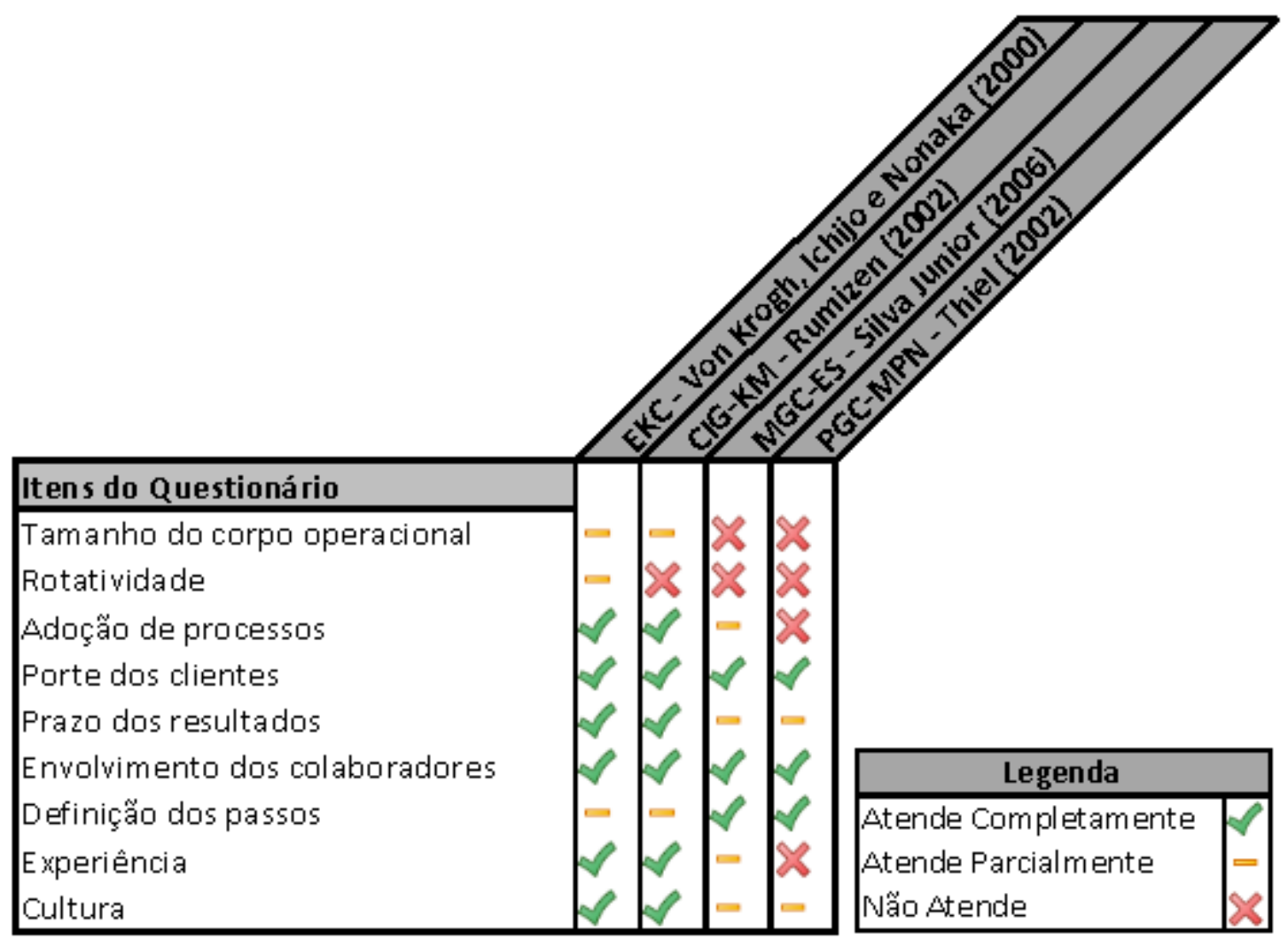

Figura 1 - Quesitos das MPEs e modelos de GC analisados

Fonte: Adaptado de Mota (2011)

Mota (2011) conclui que os modelos analisados não são totalmente adequados às características e necessidades das MPEs, mas que o modelo EKC, diferente dos outros, não falha ao atender nenhuma das nove categorias escolhidas, sendo o mais próximo das necessidades das MPEs ${ }^{1}$.

\footnotetext{
${ }^{1}$ Para maior entendimento e aprofundamento da avaliação dos modelos de GC frente às características das MPEs, sugere-se a leitura da dissertação de Mota (2011), ou de artigo posterior (MOTA; TARGINO, 2013).
} 
A Gestão do Conhecimento como recurso de inovação para Micro e Pequenas Empresas (MPEs): o modelo Enabling Knowledge Creation (EKC)

\section{3. modelo Enabling knowledge creation (EKC)}

O modelo descrito no livro Enabling knowledge creation, que não foi batizado pelos autores e será doravante chamado de modelo EKC, surgiu em 2000, com o desenvolvimento de um livro homônimo realizado pelos autores von Krogh, Ichijo e Nonaka. A obra é dividida em capítulos que descrevem tais etapas, sendo duas de preparação e cinco principais.

A primeira etapa de preparação cria a fundamentação para todo o processo de GC, criando uma visão organizacional que inclua o conhecimento e colaboração, fazendo os colaboradores perceberem que a GC não é apenas um subproduto dos processos organizacionais e, sim, algo essencial para seu funcionamento e distinção dos concorrentes. Essa visão, de cunho estratégico, deve ter sua base no presente, mas deixando claro onde se deseja estar no futuro e por onde ir, balanceando presente e futuro. Para isso, busca-se criar a confiança entre os funcionários, quebrando barreiras de desconfiança e timidez ao incentivar a tolerância aos erros, coragem de questionar e buscar apoio, tutoramento entre os pares e um comportamento voltado à ajuda ao próximo.

A segunda etapa discute mecanismos de gerenciamento informacional, sugerindo formas de modificar a apresentação da informação, adequando-a ao setor de destino, que irá consumir e criar novos conhecimentos. Faz-se necessário compreender não somente as necessidades, mas as especificidades de cada setor e das pessoas que ali trabalham, para melhor adequar a informação para que a compreensão seja feita da melhor forma possível. De forma semelhante, o recebimento e a recriação de conhecimento é muito importante para completar o processo.

Posterior à implementação de ambas as etapas de preparação (Quadro 2), os autores sugerem cinco etapas de aplicação do modelo EKC, como mostra o Quadro 3. As etapas desse modelo não focam no processamento de informações e conhecimentos dos indivíduos da organização, mas na "habilitação" da colaboração entre estes. Isso pode ser percebido no título do livro e dos capítulos que explanam as etapas, iniciados com derivações da palavra enable, que significa habilitar, capacitar ou possibilitar. Dessa forma, a cada etapa os autores buscam capacitar as pessoas envolvidas no processo a realizar alguma ação que permitirá a melhor cooperação e intercâmbio de informações e conhecimentos entre os pares. 
André Anderson Cavalcante Felipe e Denysson Axel Ribeiro Mota

Quadro 2 - Etapas de implementação do modelo EKC

\begin{tabular}{c} 
Visão organizacional \\
(relação entre conhecimento, colaboração e confiança) \\
Gerenciamento informacional \\
(consumo e criação de novos conhecimentos) \\
\hline Fonte· VON KROGH; ICHUO; NONAKA, 2000
\end{tabular}

Fonte: VON KROGH; ICHIJO; NONAKA, 2000.

Quadro 3- Etapas de aplicação do modelo EKC

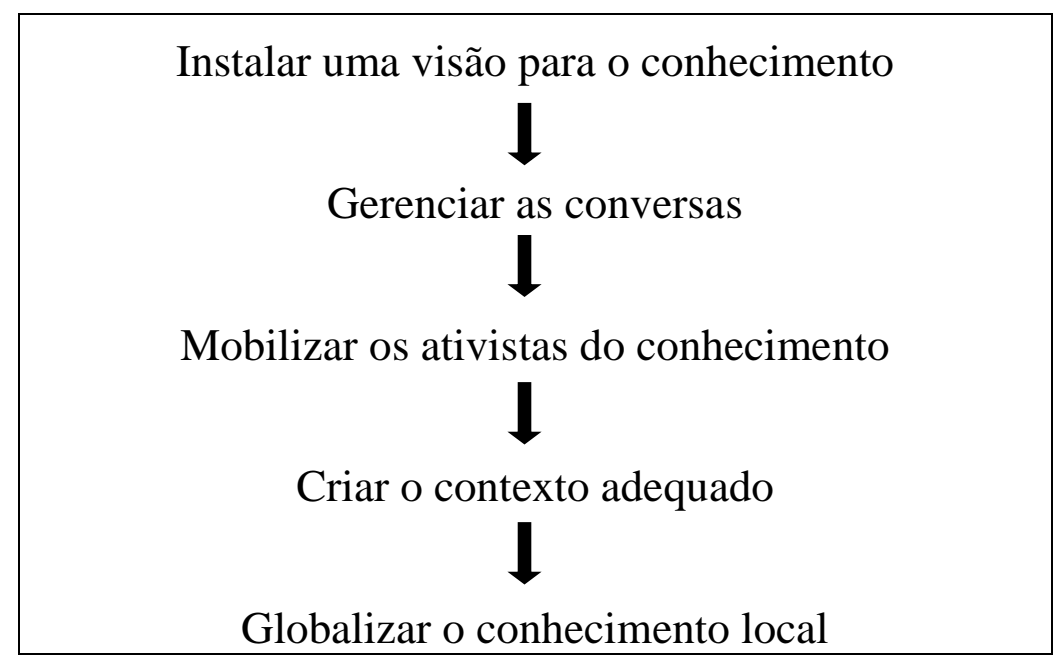

Fonte: VON KROGH; ICHIJO; NONAKA, 2000.

A primeira etapa do modelo EKC, denominada de Enabler 1: Instill a Knowledge Vision (Instilar a visão do conhecimento), apresenta fases que devem ser realizadas com os colaboradores da organização, em reuniões de brainstorming de escopo ilimitado, sem limites de assuntos ou de alcance de tratamento para cada um. Todos os conceitos que surgem dessa reunião são importantes por serem elementos que surgem das bases da organização, dando confiança aos colaboradores por fazerem parte de toda a estratégia organizacional e, não tratar todo o processo como algo imposto, principalmente ao se ter o elemento pessoal, de situação atual e futura, e não apenas o organizacional. O objetivo é criar a visão, na organização, tanto de forma explícita nos objetivos organizacionais, como implícita nos colaboradores, que o conhecimento é necessário para alcançar as metas traçadas.

Um passo interessante, e que alguns modelos costumam ignorar, é o de esperar. Ações que envolvem relações interpessoais, principalmente voltadas para mudanças comportamentais e criação de confiança, demoram a surtir os efeitos desejados, por isso a paciência aqui é chave. Prosseguir para etapas seguintes sem alcançar os objetivos 
A Gestão do Conhecimento como recurso de inovação para Micro e Pequenas Empresas (MPEs): o modelo Enabling Knowledge Creation (EKC)

delimitados trará mais malefícios que benefícios, por isso é importante esperar e analisar se as ações estão ocorrendo como esperado. Os autores também comentam sobre a importância que todos os colaboradores, independente de cargo ou posição, vejam todo o processo como algo criativo, voltado para o conhecimento individual e coletivo, e que deve alcançar não apenas os objetivos organizacionais, mas também os desejos individuais de carreira e aprendizado.

A segunda etapa, Enabler 2: Manage Conversations (Gerenciar as conversas), busca gerencias as conversas, tanto oficiais como casuais. Para os autores, o diálogo é o centro de toda atividade de conhecimento, e esta etapa não somente afeta todas as fases de criação de conhecimento, como também é a mais relevante entre as outras etapas do modelo. Apesar de que, segundo os autores, as atividades de gerenciamento da comunicação envolvem cerca de $80 \%$ das atividades de gestão, não há script definido que garanta resultados ótimos. Há, no entanto, uma série de itens que, se seguidos, auxiliam a correta execução desta etapa.

A primeira recomendação é encorajar, ativamente, a participação entre os colaboradores, ficando à vontade para interferir de forma espontânea caso tenha alguma ideia, sem medo de repreensões ou represálias de chefes ou colegas. Para garantir o respeito e diminuir ocasiões de mal entendidos, é necessário criar uma etiqueta para as conversas, que guiarão todos os diálogos organizacionais, ditando comportamentos e palavras aceitáveis ou não. Nessa linha, a condução da conversa, terceiro elemento, é importante quando ocorrem palavras ambíguas, discutindo os conceitos ou significados possíveis até que se chegue a um consenso aceitado por todos de forma espontânea, não imposta. Isso é importante ao considerar o quarto item, que encoraja linguagem inovadora, criando novas palavras e conceitos quando se percebe que com os conceitos usuais não se consegue expressar o que se deseja.

O Enabler 3, Mobilize Knowledge Activists (Mobilizar os ativistas do conhecimento), tem como objetivo conscientizar as pessoas na organização que foram identificadas, em etapas anteriores, como líderes na criação de conhecimento dentro da organização, incentivando e iniciando o diálogo e guiando as pessoas durante essa atividade. É importante perceber que o ativista não é necessariamente, aquele que dá mais, ou melhores, ideias, mas sim o que tem a iniciativa de iniciar e focar a criação de conhecimento, e consegue preparar as pessoas para melhor colaborar. $\mathrm{O}$ ativista geralmente atua em um ou mais dos seguintes papéis: catalizador, coordenador e mercador. Cada um desses papéis tem características e 
funções bem específicas, e seu correto desempenho irá depender das habilidades do ativista, habilidades estas sintetizadas no Quadro 4.

Quadro 4 - Habilidades desejadas nos ativistas do conhecimento

\begin{tabular}{|l|l|l|}
\hline \multicolumn{1}{|c|}{ Catalizador } & \multicolumn{1}{|c|}{ Coordenador } & \multicolumn{1}{c|}{ Mercador } \\
\hline Habilidades motivacionais & $\begin{array}{l}\text { Compreensão histórica do } \\
\text { crescimento da empresa }\end{array}$ & $\begin{array}{l}\text { Embaixador da visão } \\
\text { organizacional para o } \\
\text { conhecimento }\end{array}$ \\
\hline $\begin{array}{l}\text { Habilidades interpessoais: } \\
\text { respeitado }\end{array}$ & $\begin{array}{l}\text { Habilidades narrativas: } \\
\text { detectar, formular e contar } \\
\text { estórias de criação de } \\
\text { conhecimento }\end{array}$ & $\begin{array}{l}\text { Habilidades em análise e } \\
\text { ferramentas estratégicas }\end{array}$ \\
\hline $\begin{array}{l}\text { Habilidades intervencionais: } \\
\text { melhorar relacionamentos e } \\
\text { dinâmica de grupo }\end{array}$ & $\begin{array}{l}\text { Habilidades visuais e } \\
\text { cartográficas: criar e manter } \\
\text { mapas compartilhados de } \\
\text { cooperação }\end{array}$ & $\begin{array}{l}\text { Ampla compreensão dos } \\
\text { processos estratégicos da } \\
\text { organização }\end{array}$ \\
\hline $\begin{array}{l}\text { Habilidades analíticas: ajudar } \\
\text { ao grupo a desenvolver um } \\
\text { quadro com suas tarefas e } \\
\text { responsabilidades }\end{array}$ & $\begin{array}{l}\text { Habilidades analíticas: } \\
\text { desenhar conexões entre } \\
\text { iniciativas criadoras de } \\
\text { conhecimento }\end{array}$ & $\begin{array}{l}\text { Habilidades motivacionais e } \\
\text { em vender ideias }\end{array}$ \\
\hline $\begin{array}{l}\text { Aumentar a rede social } \\
\text { dentro e fora da organização }\end{array}$ & $\begin{array}{l}\text { Aumentar a rede social } \\
\text { dentro e fora da organização }\end{array}$ & $\begin{array}{l}\text { Pensamento fora do } \\
\text { convencional e habilidades } \\
\text { visionárias }\end{array}$ \\
\hline $\begin{array}{l}\text { Compreensão operacional do } \\
\text { negócio, produtos-chave e } \\
\text { mercados }\end{array}$ & & \\
\hline
\end{tabular}

Fonte: Adaptado de (VON KROGH; ICHIJO; NONAKA, 2000).

O Enabler 4: Create the Right Context (Criar o contexto adequado), visa criar um ambiente propício para a criação de conhecimento. Esse ambiente envolve três elementos ou espaços: espaços físicos, espaços virtuais e espaços mentais. Somente com a junção de todos os três é que será possível obter o ambiente perfeito, chamado pelos autores de $b a$. As mudanças necessárias para a criação desse ambiente são realizadas com a ajuda e apoio de todos os colaboradores, mas é necessário ter alguma pessoa ou setor encarregado de guiar essas mudanças.

Como cada ambiente será, no entanto, dependerá de diversos fatores: a organização, o setor, o conhecimento que deve ser criado, o conhecimento existente, a relação entre os indivíduos, entre outros. Assim, percebe-se que um estudo organizacional é necessário para a criação do ambiente adequado, mas também do negócio e do fluxo informacional, que criará o 
A Gestão do Conhecimento como recurso de inovação para Micro e Pequenas Empresas (MPEs): o modelo Enabling Knowledge Creation (EKC)

conhecimento, além de priorizar as características presentes em cada setor, para propiciar a comunicação e participação entre os colaboradores.

O Enabler 5: Globalize Local Knowledge (Globalizar o conhecimento local), último do modelo busca divulgar o conhecimento, criado localmente, para todos aqueles interessados, também entre empresas parceiras. Essa etapa inicia-se com a percepção de que conhecimento é necessário em algum lugar da empresa, ou de parceiros, o que irá desencadear o procedimento de divulgação. Para isto ocorrer, é necessário que tanto criadores como consumidores de conhecimento estejam sempre atentos a oportunidades ou necessidades não claras.

Os autores recomendam o uso de ferramentas, físicas ou virtuais, para divulgação de uma lista dos especialistas em cada área, novos conhecimentos criados pelos diferentes setores, novos projetos, contratos e tecnologias desenvolvidas. Isso permitirá que qualquer indivíduo na organização perceba possíveis conhecimentos necessários e quem pode provê-lo, mesmo que não esteja diretamente envolvido no processo.

Quando finalizadas, as etapas (enablers), a criação de conhecimento ocorrerá de forma natural, sendo este um processo não cíclico, mas de implantação de costumes locais que permitirão a criação de conhecimento não somente inter-setorial, mas inter-organizacional. Essa criação de conhecimento é o primeiro passo para a inovação, especialmente em empresas de tecnologia e micro e pequenas empresas que por terem em seu quadro funcional, caracteristicamente, poucos colaboradores, facilita o processo comunicacional entre os indivíduos (SEBRAE, 2007; MOTA, 2011). 


\section{Relação do modelo EKC com as diretrizes do SEBRAE para inovação em MPEs}

Mediante ao aporte teórico da abordagem qualitativa e da pesquisa bibliográfica, comparamos as etapas do modelo EKC com as diretrizes do SEBRAE, expondo quais as etapas mais relacionadas com as diretrizes apresentadas, bem como, as formas como estas etapas contribuem para a inclusão destas diretrizes em MPEs.

A relação entre elas no modelo EKC foram analisadas de forma comparativa baseada em argumentação lógica, utilizando como base o referencial teórico exposto nas seções anteriores.

Optamos em apontar as etapas do modelo EKC e as suas relações com a diretrizes para inovação estabelecidas pelo SEBRAE, a começar pela etapa inicial de preparação, e o primeiro enabler, Instilar a visão do conhecimento, se relacionam diretamente com a preparação necessária para todos os outros enablers, afetando também, indiretamente, as outras diretrizes, mas terá impacto direto com a diretriz 10 - Voltar atrás em tempo hábil, por definir as estratégias de sobrevivência e avanço. No caso da primeira, de sobrevivência, elas permitirão o reconhecimento das habilidades organizacionais, e definirão como proceder para manter o status quo da organização, mantendo crescimento e rentabilidade estáveis. As de avanço, por outro lado, visam o crescimento e desenvolvimento organizacional. Dessa forma, caso ocorra algo nas estratégias de avanço que não dê os resultados esperados, as estratégias de sobrevivência garantirão que seja possível retornar a um estado anterior, e possibilitarão a identificação do melhor momento para fazer isso.

O enabler 2 Gerenciar as conversas e o enabler 5 Globalizar o conhecimento local se relacionam com as diretrizes 3 - Ouça e coloque-se no lugar dos seus clientes, 4 - Saiba o que a concorrência está fazendo, 5 - Rede de relacionamento, 6 - Comunicação interna e 7 - Comunicação externa, por serem etapas voltadas à comunicação dos colaboradores, tanto de forma interna como externa, com a finalidade de estimular a colaboração entre os pares, atribuição que, no caso das MPEs, qualquer colaborador seria capaz de realizar. É importante frisar que o modelo inibe as ações desfavoráveis de colaboradores experientes nos novatos, mesmo inconscientemente, como interromper os colegas ou inibi-los, provocando que estes evitem participações futuras.

Os passos destas etapas são voltados para o controle de conversas e divulgação de informações e conhecimento, fazendo com que os colaboradores compartilhem o que sabem, 
A Gestão do Conhecimento como recurso de inovação para Micro e Pequenas Empresas (MPEs): o modelo Enabling Knowledge Creation (EKC)

e criem novo conhecimento, a partir de diálogos e reuniões. Quando visto desse modo, percebe-se que toda organização, no sentido mais amplo da palavra, já realizam as atividades sugeridas pelos autores, desde uma família até as multinacionais.

É possível concluir que esta etapa é especialmente favorável às MPEs, independente do campo de atuação ou natureza do negócio. Isso ocorre pela facilidade que se tem ao tratar das conversas, abstraindo fatores tecnológicos, como técnicas de armazenamento e recuperação de informações, e, também, processos mais complicados, para coordenação dos setores e para a tomada de decisões do projeto, que os modelos costumam ter.

O enabler 3 Mobilizar os ativistas do conhecimento, proporciona melhorias nas diretrizes 1 - Liderança inovadora e 8 - Reconhecimento e recompensa, por sugerir que exista um líder interno em cada equipe, e não um chefe, que irá iniciar e guiar as conversas, buscando incentivar os colaboradores à colaboração entre eles, assim como incentiva, reconhece e recompensa os colaboradores que participam, seja este o líder ou qualquer outro colaborador. Na fase de planejamento e no enabler "instilar a visão do conhecimento", previamente abordados, cada colaborador explicitou quais conhecimentos deseja ter em um futuro, seja a curto, médio ou longo prazo, e onde deseja estar em relação à sua própria carreira na organização. Os incentivos podem vir em relação a cursos, livros ou promoções que atinjam estes objetivos traçados.

O enabler 4 Criar o contexto adequado, pode otimizar as diretrizes 2 - Incentivar a criatividade e 9 - Capacitação, devido a seus passos que modificarão o ambiente de trabalho de cada equipe para adequá-lo à criação de conhecimento. Esse ambiente não é somente o físico, mas também o virtual e pessoal. No relativo ao ambiente virtual, isso é possível alcançar utilizando ferramentas de comunicação, como blogs, wikis, portais, entre outros. Não precisam ser criadas ferramentas específicas para a organização, apenas a adaptação para sua realidade, e por isso essas ferramentas abertas e gratuitas podem ser utilizadas sem grandes problemas. No caso do ambiente pessoal, ele pode ser modificado mediante cursos, palestras, livros, incentivo à capacitação e outras formas de recompensas, que promovam o conhecimento pessoal e estimulem a criatividade. 


\section{Considerações finais}

Diversos autores (NONAKA; TAKEUCHI, 1995; MIRANDA, 2004; BARBOSA, 2008) já abordam a GC como um fator que auxilia a incorporação de processos inovadores dentro da organização. Os autores Nonaka e Takeuchi têm, inclusive, um texto, de 1997, intitulado "Criação de conhecimento na empresa: como as empresas japonesas geram a dinâmica da inovação", completamente voltado para a geração de conhecimento voltada para a inovação, descrevendo casos de empresas japonesas. Porém, em nenhum desses casos, avaliam especificamente a perspectiva das Micro e Pequenas Empresas e como elas poderiam atingir essa inovação.

O trabalho aqui apresentado buscou contrapor dois trabalhos: o do SEBRAE (2013) com suas diretivas para a inovação, e o de von Krogh, Ichijo e Nonaka (2000) e seu modelo presente no livro Enabling Knowledge Creation. A proposta aqui foi contemplar ações voltadas especificamente para o universo das MPEs, com o estudo do SEBRAE, órgão de apoio especializado neste universo, e um modelo previamente analisado sob a ótica dessas empresas (MOTA, 2011).

Diante dos fatos expostos consideramos que o modelo EKC contempla as diretrizes estipuladas pelo SEBRAE para a promoção da inovação em MPEs. É importante salientar que mesmo que, em alguns casos, as etapas/enablers não atendam 100\% das características dessas empresas elencadas em pesquisa anterior (MOTA, 2011), é possível afirmar que abrangem de forma total as diretrizes, sendo em alguns casos relacionados a mais de uma diretriz pelo fato de abordá-las indiretamente.

Obviamente o estudo aqui presente não elimina a necessidade de algumas adequações na aplicação do EKC, como explicado anteriormente (MOTA, 2011), mas ressaltamos que essa adoção é mais simples que outros modelos por se basear em estratégias leves, diálogos e ferramentas simples, em vez de processos pesados e/ou tecnologias computacionais complexas. No entanto, mesmo sem grandes adequações ou modificações no modelo, é possível obter grandes resultados mediante as etapas de planejamento e gerenciamento das conversas, que têm grande impacto na adoção de ações de GC sob a perspectiva dos autores.

Considerando o acima exposto, acredita-se que a adoção do modelo EKC, de forma total ou parcial, por atingir as diretrizes elencadas pelo SEBRAE, de modo a promover a 
A Gestão do Conhecimento como recurso de inovação para Micro e Pequenas Empresas (MPEs): o modelo Enabling Knowledge Creation (EKC)

inovação nas MPEs. Além disso, acredita-se que a divulgação do mesmo trará benefícios não somente para essas empresas, mas para a sociedade em geral.

\section{Referências}

BARBOSA, R. Gestão da informação e do conhecimento: origens, polêmicas e perspectivas. Informação \& Informação, Londrina, v. 13, Número especial, p. 1-25, 2008..

BAUER, M. W.; JOVCHELOVICH, S. Pesquisa qualitativa com texto, imagem e som: um manual prático. Petrópolis: Vozes, 2002.

BIN, A. Planejamento e gestão da pesquisa e da inovação: conceitos e instrumentos. 2008. Tese (Doutorado em Geociências) - Universidade Estadual de Campinas, Instituto de Geociências, 2008. Cap. 1.

BRASIL. Lei Complementar $\mathrm{n}^{\circ}$ 123, de 14 de dezembro de 2006. Institui o Estatuto Nacional da Microempresa e da Empresa de Pequeno Porte; altera dispositivos das Leis no 8.212 e 8.213, ambas de 24 de julho de 1991, da Consolidação das Leis do Trabalho - CLT, aprovada pelo Decreto-Lei ${ }^{\circ} 5.452$, de 1 o de maio de 1943, da Lei ${ }^{\circ} 10.189$, de 14 de fevereiro de 2001, da Lei Complementar $n^{\circ}$ 63, de 11 de janeiro de 1990; e revoga as Leis $\mathrm{n}^{\circ}$ 9.317, de 5 de dezembro de 1996, e 9.841, de 5 de outubro de 1999. Diário Oficial da União, Brasília, 15 de dez. 2006, p. 1.

COSTA, B. K.; ALMEIDA, M. I. R. (Org.). Estratégia: direcionando negócios e organizações. São Paulo: Atlas, 2005. Cap. 1.

FELIPE, A. Ciência da informação e ambientes colaborativos de aprendizagem: um estudo de caso da plataforma Moodle-UFPB. 2011. Dissertação (Mestrado em Ciência da Informação) - Universidade Federal da Paraíba, 2011.

FIGUEIREDO, S. O que há de mais humano na gestão. Revista GC Brasil, n.1, p.10-13, 2006. Disponível em: 〈http://sbgc.org.br/publicacoes/revista-gc-brasil/>. Acesso em: 03 jul. 2014.

GIL, A. C. Como elaborar projetos de pesquisa. 4. ed. São Paulo: Atlas, 2008.

GONZÁLEZ DE GOMEZ, M. N. Metodologia de pesquisa no campo da Ciência da Informação. DataGramaZero, Rio de Janeiro, v. 1, n. 6, dez. 2000.

Novas fronteiras tecnológicas das ações de informação: questões e abordagens.

Ciência da Informação. Brasília, v. 33, n. 1, p. 55-67, jan./abril 2004.

LACERDA, S. Capacitação profissional e o novo cenário das organizações. 2010.

Disponível em: <http://www.administradores.com.br/artigos/marketing/capacitacaoprofissional-e-o-novo-cenario-das-organizacoes/46146/>. Acesso em: 28 ago. 2014. 
LIMA, J. Liderança e tomada de decisão na organização. 2012. Disponível em: $<$ http://www.uniedu.sed.sc.gov.br/wp-content/uploads/2014/01/Josimara-Alves-deLima.pdf>. Acesso em: 28 ago. 2014.

MARCHIORI, M. Os Desafios da comunicação interna nas organizações. 2008. Disponível em: <http://www.uel.br/grupoestudo/gecorp/images/os_desafios_de_comunica \%C3\% A7\%C3\%A3p_interna_intercom.pdf>. Acesso em: 28 ago. 2014.

MIRANDA, R. C. R. Gestão do conhecimento estratégico: uma proposta de modelo integrado. 2004. 289 f. Tese (Doutorado) - Programa de Pós-Graduação em Ciência da Informação, Faculdade de Economia, Administração e Contabilidade, Universidade de Brasília, Brasília, 2004.

MOTA, D. Modelos de gestão do conhecimento e micro e pequenas empresas: estudo em empresas de base tecnológica. 2011. Dissertação (Mestrado em Ciência da Informação) Universidade Federal da Paraíba, 2011.

.; TARGINO, M. G. Modelos de gestão do conhecimento em micro e pequenas empresas. BJIS, Marília, v.7, n. Especial, p.178-200, 1. Sem. 2013.

NONAKA, I.; TAKEUCHI, H. Criação de conhecimento na empresa: como as empresas japonesas geram a dinâmica da inovação. Rio de Janeiro: Campus, 1997.

The knowledge-creating company. New York: Oxford University Press, 1995. p. 38.

RUMIZEN, M. C. The complete idiot's guide to knowledge management. Indianapolis: Alpha, 2002.

SERVIÇO BRASILEIRO DE APOIO ÀS MICRO E PEQUENAS EMPRESAS (SEBRAE). [Dados dispersos]. 2014. Disponível em: < http://www.sebrae.com.br>. Acesso em: 03 jul. 2014.

. Conheça 10 dicas para estimular a inovação. 2013. Disponível em:

<http://www.sebraesp.com.br/index.php/40-noticias/inovacao/7735-conheca-10caracteristicas-inovadoras>. Acesso em: 01 maio 2014.

Fatores condicionantes e taxa de mortalidade das MPE Sergipe 2005. Brasília: Ed. Sebrae, 2007.

Sebrae, 1998.

No Brasil as pequenas empresas sabem com quem contar. Brasília: Ed.

SILVA, T. Liderança inovadora com foco gestão pessoas. 2011. Disponível em: <http://www.rh.com.br/Portal/Lideranca/Artigo/7519/lideranca-inovadora-com-foco-gestaopessoas.html>. Acesso em: 28 ago. 2014.

SILVA JÚNIOR, C. R. Um modelo para gestão do conhecimento em empresas de software. 2006. 148 p. Dissertação (Mestrado) - Programa de Pós-Graduação em Ciência da Computação. Centro de Informática. Universidade Federal de Pernambuco, Recife, 2006. 
A Gestão do Conhecimento como recurso de inovação para Micro e Pequenas Empresas (MPEs): o modelo Enabling Knowledge Creation (EKC)

SOUTO, K. Redes sociais nas organizações numa reflexão psicológica. 2013. Disponível em: <http://psicologado.com/abordagens/comportamental/redes-sociais-nas-organizacoesnuma-reflexao-psicologica>. Acesso em: 28 ago. 2014.

TARGINO, M. G. A interdisciplinaridade da ciência da informação como área de pesquisa. Informação \& Sociedade: Estudos, João Pessoa, v. 5, n. 1, p. 12-17, jan./dez. 1995.

TERRA, J. C. C. Gestão do conhecimento aspectos conceituais e estudo exploratório sobre as práticas de empresas brasileiras. 1999. 230 f. Dissertação (Mestrado em Administração) - Programa Pós Graduação em Administração. Escola Politécnica da USP, 1999.

THIEL, E. E. Proposta de um modelo de implantação de um projeto de gestão do conhecimento com base em processos organizacionais. 2002, 182f. Dissertação (Mestrado) - Programa de Pós-Graduação em Engenharia de Produção, Centro Tecnológico, Universidade Federal de Santa Catarina, 2002.

VON KROGH, G.; ICHIJO, K.; NONAKA, T. Enabling knowledge cration: how to unlock the mistery of tacit knowledge and release the power of innovation. New York: Oxford University Press, 2000. 